\title{
CLINICAL EVALUATION OF PULPOTOMY OF PRIMARY MOLARS APPLYING PROPOLIS VERSUS FORMOCRESOL
}

\author{
Abd-El Moneim S* El Bayoumy $\mathrm{S}^{* *}$ and Barakat I**
}

\begin{abstract}
Aim: The purpose of this study was to clinically evaluate applying propolis versus formocresol as a pulpotomy material in exposed primary molars. Methods: This study included 60 primary molars in 60 children 4-9 years of age who underwent an identical conventional pulpotomy technique; the molars were allocated to propolis, Formocresol groups. The patients were recalled after an interval of 1 monthand 3 months for clinical and radiographic evaluation. Results: The clinical success rates according to presence or absence of pain swelling sensitivity to percussion for propolis group were 93\%, 100\%, 100\% respectively after 1 month and 90\%, 93\%, 96\% after 3 months and for fc group it was 96\%, 100\%, 100\%after 1 month and 93\%, 96\%, 96\% after 3 months which indicates that there was no significant difference between the two materials. And for radiographic examination therewasno significant difference between the two materials at one month, three months intervals regarding root resorption and periapical radiolucency Conclusions: it could be concluded that propolis offers good clinical and radiographical results when compared with formocresol, but with no statistically significant differences
\end{abstract}

\section{INTRODUCTION}

Maintaining the involved pulp of deciduous teeth, in a healthy state until the time of normal exfoliation remains to be one of the challenges for Pedodontics ${ }^{(1,2)}$. Premature loss of primary teeth can lead to malocclusion besides functional and esthetic problems. Therefore, preserving the vitality of deciduous teeth until their natural exfoliation time is critical for maintaining the arch integrity. The pulp in primary dentition is histologically similar to permanent teeth and may be affected by caries, restorative procedure and trauma ${ }^{(3)}$. In pediatric dentistry, pulpotomy is a common therapy performed in a primary molar with extensive caries but without evidence of radicular pathology when caries removal results in a carious or mechanical pulp exposure ${ }^{(4,5)}$. This technique is one of the common treatments for of cariously exposed pulps in symptom free primary teeth; the procedure helps to maintain the integrity of primary teeth that have inflammation limited to coronal pulp. The main goal is to preserve the radicular pulp, maintain vitality and ultimately to retain the tooth ${ }^{(6)}$. Historically, the first pulp capping procedure was performed in 1756, by the Phillip Pfaff, who packed a small piece of gold over an exposed vital pulp to promote healing. However, the success of the pulp capping procedure greatly depends upon the circumstances under which it is performed and the prognosis depends upon the age, type, site and size of pulp exposure ${ }^{(7)}$. A diverse range of chemicals have been used as pulpotomy agents. As most of these have not been subjected to rigorous clinical trials, their use has been based expert opinion and retrospective studies. The available evidence suggested that formocresol, ferric sulphate, electrocautery and MTA have similar efficacy. Calcium hydroxide appears to have a consistently lower success rate

\footnotetext{
*Dentist at ministry of health

** Professor and Head, of Pedodontics and Oral Health Department Faculty of Dental Medicine Al-Azhar University (Boys - Cairo)

*** Lecturer of Pedodontics and Oral Health Department Faculty of Dental Medicine Al-Azhar University (Boys - Cairo)
} 
in pulpotomies of primary teeth than these agents. There are a number of other materials that are of historical significance, or have regional usage, and a number of experimental techniques including bone morphogenic protein and growth factors ${ }^{(8)}$. Propolis was used at the time of Egyptian and Greek civilizations which recognized its healing qualities. Hippocrates, the founder of modern medicine used it for healing sores and ulcers internally and externally. The word propolis (Russian Penicillin) is derived from the Greek word "pro" before, polis "city" or defender of the city. Propolis has been shown to possess potent antimicrobial and anti-inflammatory properties. The main chemical classes present in propolis are flavonoids, phenolics and other various aromatic compounds. Flavonoids and caffeic acid present in propolis are known to play an important role in reducing the inflammatory response ${ }^{(9)}$.

\section{MATERIALS AND METHODS}

This study was carried out on sixty primary molars selected from sixty children from the Pedodontics Outpatients Clinic, Faculty of Dental Medicine, Al-Azhar University. The age of children was ranged from 4 to 9 years.

\section{Inclusion criteria:}

These primary molars were selected according to the following criteria:

A. The tooth should be vital on testing with vitality tests (thermal).

B. The tooth should have deep carious lesions.

\section{Exclusion criteria:}

1. History of spontaneous, unprovoked toothache has been recalled.

2. Mobility.(Grade I, II and III)

3. Sensitivity for percussion.

The treatment plan was explained to the parents and their written consent was signed before the study.

\section{Clinical procedures}

Sixty primary molars were randomly assigned into two groups $(n=30)$, according to pulp capping material

Group A): Comprising 30 primary molars that were treated with Propolis.

Group B): Comprising 30 primary molars that were treated with formocresol

Based on the clinical/radiographic assessment and carious pulp exposure in affected molars, coronal pulpotomies were performed. In each treatment group, coronal pulp amputation was achieved with small and medium slow-speed round burs under local analgesia and rubber dam isolation. The amputation site was cleaned with a sterile spoon excavator, and the initial hemorrhage was controlled using a dry sterile cotton pellet applied with pressure. In cases with excessive and persistent hemorrhage, pulpectomy was performed, and the tooth was eliminated from the study. Complete hemostasis then was achieved as follows, depending on the group assignment.

- In the FC group, the sterile cotton pellets were placed in 19\% formaldehyde Buckley's FC solution. They were immediately blotted dry using a sterile cotton roll. The cotton pellet was placed directly over the radicular pulp stumps and left for $5 \mathrm{~min}$ for fixation

- In the propolis group, the procedure was completed with the placement of propolis capping material. Propolis powder was mixed with propylene glycol and gently placed on theremaining pulp tissues at the orifice of the ridiculer pulp.

\section{Follow-up}

Primary molars selected from sixty children were followed up clinically and radiographically at an interval of one month and three months according topain, mobility, sensitivity to percussion, swelling, root resorption and periapical radiolucency. 


\section{Statistical analysis}

The data collected was tabulated and statistically analyzed. The statistical test used for the study was the Chi-squared $\left(\chi^{2}\right)$ test. The statistical analysis was done in Microsoft Excel software. The Chisquare test was used to test assolciation using the following formula: $P$ value of 0.05 or less was considered for statistical significance.

\section{RESULTS}

Comparison between group A (propolis) and group B (formocresol):

\section{According to presence or absence of pain:}

Chi square test showed statistical non-significant difference regarding different investigation times ( $>>0.05)$ Table 1

TABLE (1) Comparison between the two groups according to pain

\begin{tabular}{|c|c|c|c|c|c|c|}
\hline \multirow[t]{2}{*}{ Pain } & \multicolumn{2}{|c|}{$\begin{array}{l}\text { Test teeth } \\
\text { (Propolis) } \\
(n=30)\end{array}$} & \multicolumn{2}{|c|}{$\begin{array}{l}\text { Control teeth } \\
\text { (Formocresol) } \\
\quad(n=30)\end{array}$} & \multirow[t]{2}{*}{$\chi^{2}$} & \multirow[t]{2}{*}{${ }^{\mathrm{FE}} \mathrm{p}$} \\
\hline & No. & $\%$ & No. & $\%$ & & \\
\hline \multicolumn{7}{|c|}{1 months } \\
\hline No & 28 & 93.3 & 29 & 96.7 & \multirow{2}{*}{$\begin{array}{l}\tilde{n} \\
\text { ?n } \\
0\end{array}$} & \multirow{2}{*}{1.000} \\
\hline Yes & 2 & 6.7 & 1 & 3.3 & & \\
\hline \multicolumn{7}{|c|}{3 months } \\
\hline No & 27 & 90.0 & 28 & 93.3 & \multirow{2}{*}{$\frac{\infty}{\stackrel{\sim}{0}}$} & \multirow{2}{*}{1.000} \\
\hline Yes & 3 & 10.0 & 2 & 6.7 & & \\
\hline
\end{tabular}

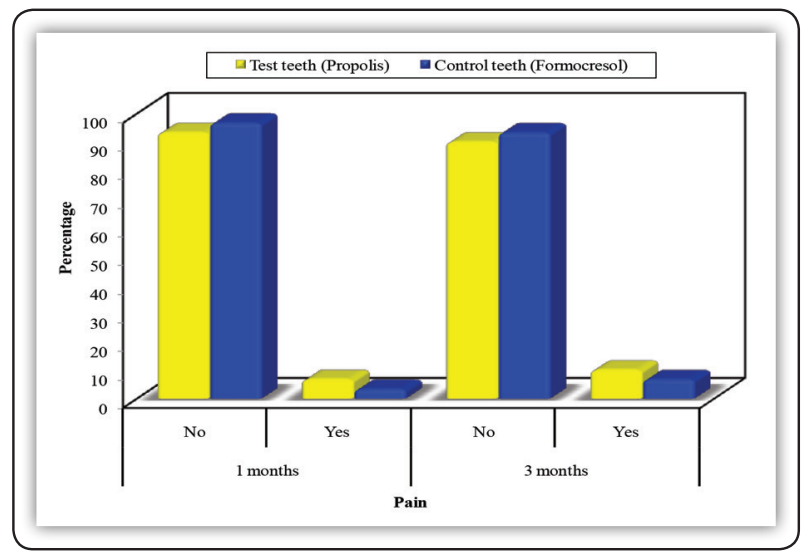

FIG (1) Comparison between the two groups according to pain

\section{According to presence or absence of swelling:}

Chi square test showed statistical non-significant difference regarding different investigation times (p>0.05). (table 2)

TABLE (2) Comparison between the two groups according to swelling

\begin{tabular}{|c|c|c|c|c|c|c|}
\hline \multirow[t]{2}{*}{ Swelling } & \multicolumn{2}{|c|}{$\begin{array}{l}\text { Test teeth } \\
\text { (Propolis) } \\
(\mathrm{n}=30)\end{array}$} & \multicolumn{2}{|c|}{$\begin{array}{l}\text { Control teeth } \\
\text { (Formocresol) } \\
\quad(n=30)\end{array}$} & \multirow[t]{2}{*}{$\chi^{2}$} & \multirow[t]{2}{*}{${ }^{\mathrm{FE}} \mathrm{p}$} \\
\hline & No. & $\%$ & No. & $\%$ & & \\
\hline \multicolumn{7}{|l|}{1 months } \\
\hline No & 30 & 100.0 & 30 & 100.0 & \multirow{2}{*}{ - } & \multirow{2}{*}{ - } \\
\hline Yes & 0 & 0.0 & 0 & 0.0 & & \\
\hline \multicolumn{7}{|l|}{3 months } \\
\hline No & 28 & 93.3 & 29 & 96.7 & \multirow{2}{*}{0.351} & \multirow{2}{*}{1.000} \\
\hline Yes & 2 & 6.7 & 1 & 3.3 & & \\
\hline
\end{tabular}

$\chi^{2}, p: \chi^{2}$ and $p$ values for Chi square test for comparing between the two groups

FE: Fisher Exact for Chi square test

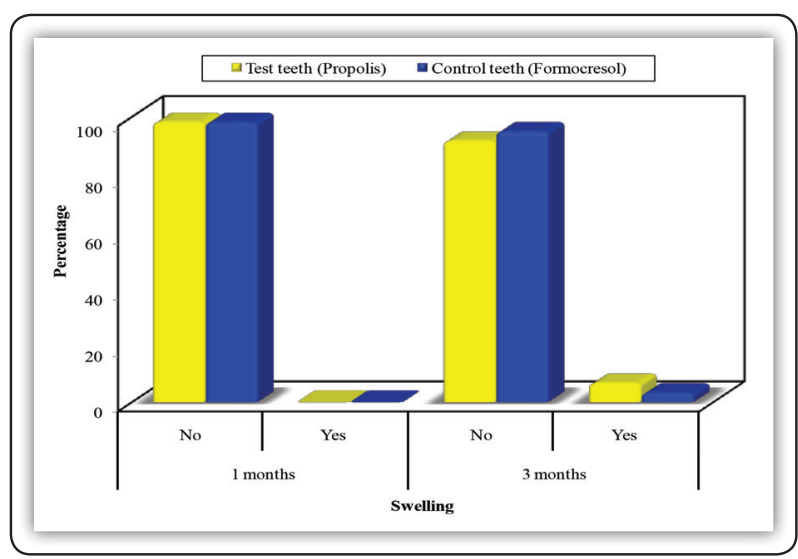

FIG (2) Comparison between the two groups according to swelling

\section{According to presence or absence of periapical radiolucencys}

Chi square test showed statistical non-significant difference regarding different investigation times ( $>0.05)$. (table 3) 
TABLE (3) Comparison between the two groups according to periapical radiolucency

\begin{tabular}{|c|c|c|c|c|c|c|}
\hline \multirow{2}{*}{$\begin{array}{c}\text { Periapical } \\
\text { radiolucency }\end{array}$} & \multicolumn{2}{|c|}{$\begin{array}{c}\text { Test teeth } \\
\text { (Propolis) } \\
(\mathrm{n}=30)\end{array}$} & $\begin{array}{c}\text { Control teeth } \\
\text { (Formocresol) } \\
(\mathrm{n}=30)\end{array}$ & \multirow{2}{*}{$\chi^{2}$} & \multirow{2}{*}{${ }^{\mathrm{FE} p}$} \\
\cline { 2 - 5 } No. & $\%$ & No. & $\%$ & & \\
\hline 1 months & & & & & & \\
\hline No & 29 & 96.7 & 29 & 96.7 & \multirow{2}{*}{0.000} & \multirow{2}{*}{1.000} \\
\hline 3 months & 1 & 3.3 & 1 & 3.3 & & \\
\hline No & 28 & 93.3 & 28 & 93.3 & \multirow{2}{*}{0.000} & \multirow{2}{*}{1.000} \\
\hline Yes & 2 & 6.7 & 2 & 6.7 & & \\
\hline
\end{tabular}

$\chi^{2}, p: \chi^{2}$ and $p$ values for Chi square test for comparing between the two groups

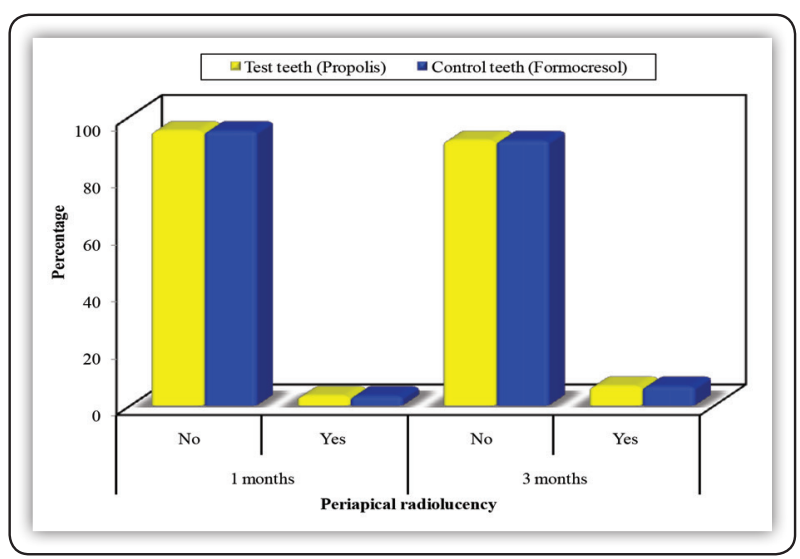

FIG (3) Comparison between the two groups according to periapical radiolucency

\section{DISCUSSION}

One of the major challenges in pediatric dentistry is to maintain pulpally involved primary teeth in a healthy stateuntil the time of normal exfoliation. Various methods have been developed in order to maintain pulp vitality inprimary teeth, such as indirect or direct pulp capping and vital pulpotomy.

In the present study, we compared formocresol with propolis in pulpotomy of primary molars and the teeth were clinically and radiographically evaluated after one month and three months respectively.

In the present study, there was no significant difference between propolis and formocresol according to pain: In agreement of this result, another investigator ${ }^{(10)}$ has shown that propolis has anti-inflammatory and pain-relieving mechanisms. It has been reported to have anti-inflammatory, antibacterial, cariostatic, desensitizing and pulp capping agent, quickens relief of dental pain. It controls neutrophil infiltration via anti-inflammatory pathways. The use of propolis as pulp capping material exerts pain killing with anti-inflammatory effect on dental pain.

In the present study, there was no significant difference between propolis and formocresol according to swelling, tooth mobility and sensitivity to percussion:In agreement of this result, another investigator ${ }^{(11)}$ concluded that propolis has antiinflammatory properties via suppressing lipoxygenase (LOX) and Cyclooxygenase (COX) enzymes during inflammation.COX-2 is mainly inhibited by flavonoid which suppresses prostaglandin-endoperoxide synthase (PTGS)at high concentration depending on the hydrophilicity and structure, whereas LOXis mainly inhibited by quercetin component of propolis. It has also been shown thatflavonoid inhibits the accumulation of mast cells. The major component of propolis is the caffeic acid phenethyl ester (CAPE) which is a biologically active compound. It has anti-inflammatory and antioxidant properties. Due to its lipophilic nature; it is easy for CAPE to enter the cells. CAPE inhibits LOX and COX enzymes that are involved in the arachidonic acid (AA) metabolism pathways. Therefore, the AA metabolism is arrestedand there is no release ofprostaglandins and leukotriene, responsible for inflammation and pain. In addition, CAPE inhibits the release of the inflammatorycytokines and simultaneously increases the production of anti-inflammatory cytokines such as interleukins IL-10and IL-4.Andit has shown that, CAPE decreasestheinfiltration of inflammatory cells such as neutrophils and monocytes. 
However, in disagreement of this result, several researches ${ }^{(12)}$ stated that allergic reactions have been reported from use of propolis. Allergic reactions may be manifested as contact cheilitis, contact stomatitis, perioral eczema, labial edema, oral pain, peeling of lips, and dyspnea. Various allergens have been isolated from propolis namely 3-methyl2-butenyl caffeate, phenyl ethyl caffeate, benzyl caffeate, geranyl caffeate, benzyl alcohol benzyl cinnammate, methyl cinnammate, ferulic acid, tectochrys. Propolis seems to be one of the most frequent contact sensitizers and should be included in routine patch testing in children and adolescents before use.

In the present study, there was no significant difference between propolis and formocresol according to root resorption and periapical radiolucency: Another researcher ${ }^{(13)}$ found that propolis was successful as a pulp capping agent on primary molars after a follow up period of up to 12 months with a success rate approaching $87 \%$ in primary teeth and $100 \%$ immature permanent teeth. Clinical examination shows decreased pain, swelling and sensitivity to percussion. Radiographic evaluation shows that periapical radiolucency is replaced by bone deposition. Propolis seems to be an effective direct pulp-capping agent in primary and immature permanent teeth.

However, in disagreement of this result, another study ${ }^{(14)}$ concluded that formocresol as pulpotomy dressing that has been most commonly used in primary molars during past several decades has potential carcinogenic and mutagenic effects which led to its limited use as pulpotomy medicament. Some natural materials from the field of traditional medicine have also been introduced as medicaments in vital pulp therapy as an alternative to commercially available artificial products such as propolis. The ethanolic extract of propolis has suggested promoting bone regeneration and induction of hard tissue bridge formation in pulpotomy and pulp capping

\section{REFERENCE}

1. Naik S, Hegde AM. Mineral trioxide aggregate as a pulpotomy agent in primary molars: An in vivo study. J Indian SocPedodPrev Dent. 2005; 23:13-16.

2. Antar F, Bacho R, AbiHatem G, Ghosn Z. Is formocresol still the medication of choice for pulpotomies in primary teeth? A literature reviews. Lebanes J Dent Med 2004; $3: 53$

3. Parisay I, Ghoddusi J, Forghani M. A review on vital pulp therapy in primary teeth Iran Endo J 2015; 10:6-15.

4. Camp J, Fuks A. Pediatric endodontics: Endodontic treatment for the primary and young permanent dentition. In: Cohen S, Hargreaves KM, editors. Pathways of the Pulp. $9^{\text {th }}$ ed. St. Louis: Mosby Elseiver; 2006;9; 822-53.

5. Sweet C. Procedure for treatment of exposed and pulpless deciduous teeth. J Am Dent Assoc 1930; 17:1150-153.

6. Gisoure1 E. Comparison of three pulpotomy agents in primary molars: A randomized clinical trial . Iran Endo J 2011; 6:11-14

7. Qureshi A, Soujanya E, Nandakumar F. Recent advances in pulp capping materials: An overview. J Clinic Diagn Res 2014; 8:3:16-`21

8. Cameron A ,Richard P. Hand book of pediatric dentistry 2013;4:115-50

9. Parolia A, Manuel S, Thomas M, Kundabala I. Propolis and its potential uses in oral health. Int. J Med Sci, 2010;2; 210-15.

10. Merlini R, Abhishek P, Allan P, Fabian D. The Role of Propolis in Inflammation and Orofacial Pain. Scien.Dom. Int. 2014; 4(4):651-664

11. Almeida E, Menezes H. Anti-inflammatory activity of propolis extracts: a review. JVenom Anim Toxins.2002; 8(2):191-212.

12. Nandini D, Basavaiah D, Deepak B. Propolis and allergic reactions J Pharm Bioallied Sci. 2012; 4(4): 345.

13. Al-afandy, Assessment of crude propolis as a direct pulp capping agent in primary and immature permanent teeth. ENDO. 2014; 8 (3):199-206.

14. Kusum B, Rakesh K, Richa K. Clinical and radiographical evaluation of mineral trioxide aggregate, biodentine and propolis as pulpotomy medicaments. Restor Dent Endod. 2015; 40(4):276-85 
